POSTER 5-47

\section{A Two-Year Review of Statewide EMT Disciplinary Investigations}

\author{
*Keith Neely, MPA, EMT-P \\ Oregon Health Sciences University, Department of Emergency \\ Medicine, Portland, Oregon
}

Objective: To determine characteristics of EMT violations and sanctions through review of state Health Division (HD) investigative records.

Methods: During a two-year period, 103 EMTs were reported to $\mathrm{HD}$ for alleged violations or were investigated because of responses made to personal history questions on their EMT applications. All were reviewed. The 7,172 EMTs recertified during the same two-year period comprised the control group. The two groups were exclusive. Age, gender, agency affiliation type, and certification level were compared (Chi-square analysis).

Results: The 103 investigated EMTs represent $1.4 \%$ of the population. Of these, 76 were male, 20 female, and the gender of seven was not recorded. Of the four EMT levels, there were proportionately fewer EMT-Basics investigated and disciplined $(p<0.05)$. The EMTs employed with private ambulances accounted for a greater proportion of investigations $(20 ; 19 \%)$ than was their respective proportion of the EMS population (564; $8 \% ; p<0.01)$. Personal history background checks were the most common reason for the investigation, generating $36 \%$ (37) of the investigations. Patients generated no complaints. Supervising physicians generated one investigation. Chemical addiction and excessive use of alcohol accounted for $25(23 \%)$ of the investigations. Misdemeanor/felony convictions and unprofessional behavior accounted for $29(28 \%)$. Denial of initial certification at the time of application was the most common action $(17 ; 16 \%)$, followed by certificate revocation in 13 $(13 \%)$. While there were no statistical differences in the type of investigation between men and women, proportionately more men than women had their certificates denied, and proportionately more women than men received reductions in their certification level. Nineteen $(18 \%)$ of investigations resulted in no action. There was no age difference between groups.

Conclusions: The incidence of investigations is small. Routine HD background checks are a very useful means of identifying EMTs in violation of the law. The supervising physician plays a small role in identifying EMTs for HD investigation. Substance abuse accounts for a significant portion of investigated cases. The differences in actions taken against men and women require further exploration.
POSTER 6-11

Emergency Ventilation Volumes: A Comparison of Commonly Used Ventilators During Two-Person Cardiac Resuscitation

\author{
${ }^{*}$ David W. Lindell, MS, EMT-P, Charles Bortle, \\ RRT, NREMT-P, Steven B. Cohen, EMT-P \\ David C. Cone, MD Steven J. Davidson, $M D$, \\ $M B A, F A C E P$ \\ Department of Emergency Medicine, The Medical College of \\ Pennsylvania, Philadelphia, Pennsylvania; EMS Education \\ Department, St. Joseph Hospital, Lancaster, Pennsylvania
}

Purpose: To compare the effectiveness of ventilations delivered by EMTs during two-person CPR using three different ventilation devices; and to gauge the participants' perceptions of device characteristics.

Methods: Using a prospective, randomized, in-vitro model, 51 self-selecting certified EMTs from six rural and semi-suburban volunteer ambulance services ventilated a mannikin (while performing two-person CPR) modified with a flow sensor installed in the trachea. Each EMT used a bag-valve-mask (BVM), a demand valve (DV), and a preset, oxygen-powered, portable ventilator (POPPV) for three minutes per device. The number of breaths per minute and the minute volume were recorded for each minute of ventilation for each device. After completing the test period, each participant completed a questionnaire in which $\mathrm{s} /$ he rated the difficulty of use for each device, provided a subjective assessment of the adequacy of ventilations, and selected which of the devices $\mathrm{s} / \mathrm{he}$ preferred.

Results: Mean tidal volumes were: $\mathrm{BVM}=498 \mathrm{ml}$; DV $=$ $524 \mathrm{ml}$; and POPPV $=770 \mathrm{ml}$. Significant differences exist between the tidal volumes achieved with the POPPV, and the other devices were identified by 2-tailed $t$-test. While participants assessed all devices as average (BVM) or easy to use (DV, POPPV), the POPPV, was considered to provide excellent ventilations and was preferred. The BVM and DV were assessed as providing only adequate ventilations.

Conclusions: The tidal volumes achieved with the POPPV approximated the AHA $800 \mathrm{ml}$ standard for ventilation and may be used effectively by EMTs. The BVM and DV were evaluated subjectively as delivering adequate ventilations when they did not. EMTs may be able to ventilate better with the POPPV than with the BVM or DV. The EMTs' subjective assessment of the adequacy of ventilation is unreliable. 